\title{
Optimizing the Two-Stage Supply Chain Inventory Model with Full Information Sharing and Two Backorders Costs Using Hybrid Geometric-Algebraic Method
}

\author{
Mohamed E. Seliaman \\ Department of Information Systems, King Faisal University, P.O. Box 78, Al-Hufof 31982, Saudi Arabia \\ Correspondence should be addressed to Mohamed E. Seliaman; mseliaman@gmail.com
}

Received 27 January 2013; Revised 12 April 2013; Accepted 19 April 2013

Academic Editor: Cedric Yiu

Copyright (C) 2013 Mohamed E. Seliaman. This is an open access article distributed under the Creative Commons Attribution License, which permits unrestricted use, distribution, and reproduction in any medium, provided the original work is properly cited.

\begin{abstract}
We consider the case of a two-stage serial supply chain system. This supply chain system involves a single vendor who supplies a single buyer with a single product. The vendor's production rate is assumed finite. In addition, the demand at the buyer is assumed deterministic. In order to coordinate their replenishment policies and jointly optimize their operational costs, the two supply chain partners fully share their relevant information. For this purpose, we develop an integrated inventory replenishment model assuming linear and fixed backorders costs. Then, we use a hybrid geometric-algebraic method to drive the optimal replenishment policy and the minimum supply chain total cost in a closed form.
\end{abstract}

\section{Introduction}

Supply chain integration is concerned with functional integration and coordination among the supply chain partners. In an independently managed supply chain, each member in each stage will optimize his own operational costs in a decentralized fashion. Generally, it has been realized that such managerial independence of the supply chain partners may increase the imbalance between demand and supply. Such independence also has been recognized as direct cause of increased costs. This pushed firms towards the full integration of the supply chain resources and the proper coordination of decisions. Researchers report that closer collaboration among the chain partners, increased level of information sharing, and high level of coordination of various decision processes lead to improved customers service and reduced costs. The significant advances in information and communication technologies facilitated the provision and sharing of the business information necessary for efficiency improvement. This, in turn, facilitated the development in the integrated supply chain management.

In recent years, numerous articles in supply chain modeling have addressed the issue of inventory coordination.
Banerjee [1] introduced the concept of joint economic lotsizing problem (JELS) for the case of a single vendor and a single purchaser under the assumption of deterministic demand and lot for lot policy. Since then, numerous articles in supply chain modeling focused on the integrated vendorbuyer inventory models and the joint economic lot-sizing problem [2-4]. An extensive review of integrated models which deal with the interaction between a buyer and vendor is presented in [5]. This review classified the literature dealing with the integrated models into four main classes. The first class represents models which deal with joint economic lot sizing policies. The second class characterizes models which deal with the coordination of inventory by simultaneously determining the order quantity for the buyer and the vendor. The third class is a group of models which deal with integrated problem but do not determine simultaneously the order quantity of the buyer and the vendor. The last class represents models which deal with buyer-vendor coordination subject to marketing considerations. In the following, we provide an overview of selected relevant models.

Goyal and Szendrovits [6] presented a constant lot size model where the lot is produced through a fixed sequence of manufacturing stages, with a single setup and without 
interruption at each stage. A one-vendor multibuyer integrated inventory model was developed in [7] with the objective of minimizing the vendor's total annual cost subject to the maximum cost that the buyer may be prepared to incur. The single-vendor multibuyers integrated inventory model was revisited by [8] where he relaxed the constraint of equal-sized shipments of [9] and suggested that the shipment size should grow geometrically.

The idea of producing a single product in a multistage serial production system was extended by [10] to deal with equal and unequal sized batch shipments between stages.

Several benefits of coordinating inventory decisions and sharing related information have been reported in the supply chain management literature. The investigation by [11] on the bullwhip effect in supply chains reported that lack of information sharing can lead to excessive inventory, poor customer service, lost revenues, unplanned capacities, and ineffective logistics. They recommend avoiding managerial independence by integrating various supply chain functions. They also recommend that firms need to device strategies that lead to smaller batches or frequent replenishments. Exchange of substantial quantities of information among the buyer, supplier, and carrier can increase the efficiency and effectiveness of the supply chain [12]. Coordinated replenishment can significantly reduce inventory. Inventory reductions have a significant impact on supply chain activities. Lower inventory levels increase operating revenues and reduce the need for costly facilities [13].

The centralized, coordinated replenishment policy and the decentralized replenishment policy in a two-echelon, multiitem supply chain were investigated in the model developed by [14]. This model determined the optimal common replenishment cycle for end items and the integer multiples of the common replenishment cycle for raw materials. Analysis showed that a centralized, coordinated replenishment policy was always found to be superior to the decentralized replenishment policy in terms of cost reduction, especially when major setup costs were high.

Most of these reviewed research articles used differential calculus to drive the optimal solutions for the integrated production inventory models. However, a recent line of research focused on easier solution methods for the optimization of these types of systems [15, 16]. For example, [17] introduced the use of algebraic optimization approach to the EOQ model with no backorders. Reference [18] used algebraic procedure to the EPQ formula taking shortages into consideration within the case of only one backlog cost per unit and time unit. Reference [19] considered an integrated three-stage inventory system with backorders. They formulated the problem to derive the replenishment policies with four-decisionvariables algebraically. Their model was later extended by [20] to include a fourth stage.

The popularity of the algebraic approach for the optimization of production inventory models could be due to the fact that it requires basic knowledge of simple elementary mathematics [21]. An exhaustive literature review on the use of algebraic optimization methods in the development of production inventory systems is presented in [21]. Interested readers are referred to the more recent relevant models presented in $[22,23]$.

In this paper, we develop a two-stage supply chain inventory model under two types of backordering costs. This model is an extension of [19], which considered only a single stage inventory system. The hybrid geometric-algebraic solution method described in this paper contributes to the trending research that uses nontraditional derivatives based methods. The main purpose of this direction of research is developing useful supply chain models that can be understood and used without the knowledge of differential calculus [19]. To the best of the authors' knowledge, there is no model in the literature of multistage supply chain modeling that used algebra and analytical geometry to drive optimal production-inventory coordination decisions with linear and fixed backorders costs.

The remainder of this paper is organized as follows. The next section presents the notation and assumptions made for developing the model. Section 3 describes the development of the model. A numerical example illustrating the model application is presented in Section 4 . Section 5 contains some concluding remarks.

\section{Notations and Assumptions}

2.1. Notations. The following notations are used in developing the model:

$T$ : basic cycle time, cycle time at the end buyer,

$S_{b}$ : setup cost for the buyer,

$D$ : the demand rate for the buyer,

$S_{v}$ : setup cost for the vendor,

$K_{v}$ : integer multiplier at vendor,

$h_{r}$ : inventory holding cost per unit time for the buyer,

$h_{v}$ : inventory holding cost per unit time for the vendor,

$T_{S}$ : the stock-out time at the buyer,

$\widehat{\pi}$ : backordering cost per unit per unit time (linear) for the buyer,

$\pi$ : per unit backorder cost (fixed) for the buyer.

2.2. Assumptions. The following assumptions are made for the two-stage supply chain model:

(a) a single product is produced by the vendor and transferred to the buyer;

(b) replenishment is instantaneous;

(c) production rate and demand rate are deterministic and uniform;

(d) a lot produced by the vendor and sent in equal batches to the buyer;

(e) complete information sharing policy is adopted;

(f) there are two types of backorders costs. 


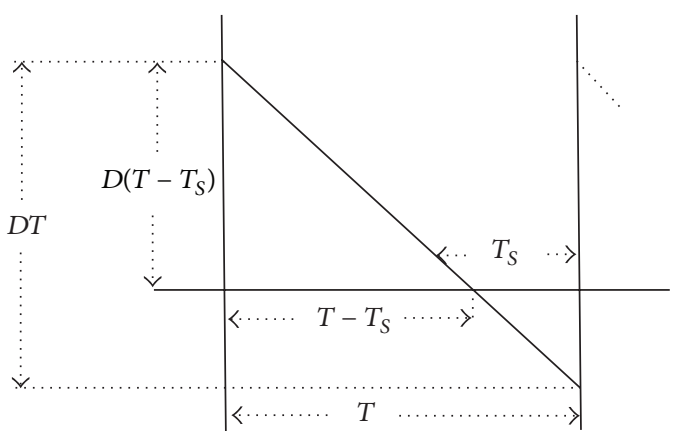

FIGURE 1: The buyer's inventory level behavior.

\section{Model Development}

We consider a two-stage serial supply chain consisting of a single vendor and a single buyer. This supply chain model is formulated for the integer multiplier inventory replenishment coordination mechanism, where the cycle time at the vendor is an integer multiple of the inventory replenishment cycle time used by the buyer. Shortages are allowed for the end buyer. The buyer's cost consists of the inventory holding cost, the shortage costs, and the setup cost. Figure 1 shows the inventory pattern for the buyer.

As we can see from Figure 1, the total annual cost for the buyer is given by

$$
T C_{b}=h_{b} \frac{T D}{2}-T_{S} D h_{b}+h_{b} \frac{T_{S}^{2} D}{2 T}+\widehat{\pi} \frac{T_{S}^{2} D}{2 T}+\pi \frac{T_{S} D}{T}+\frac{S_{b}}{T} .
$$

This total annual cost can be rewritten as

$$
T C_{b}=h_{b} \frac{T D}{2}+T_{S} D\left(\frac{\pi}{T}-h_{b}\right)+\frac{T_{S}^{2} D}{2 T}\left(\hat{\pi}+h_{v}\right)+\frac{S_{b}}{T} .
$$

The total costs at the vendor side are made of three parts. The first part is the cost of carrying inventory of raw materials as they are being converted into finished products during the production portion of the cycle. The second part is the cost carrying inventory of the finished products during the nonproduction portion of the cycle [2]. The third part is the setup cost. Therefore, the total cost for the vendor is

$$
T C_{v}=K_{v} \frac{T D^{2}}{2 P_{v}}\left(h_{r}+h_{v}\right)+\left(K_{v}-1\right) \frac{T D}{2} h_{v}+\frac{S_{v}}{K_{v} T} .
$$

The total cost for the entire supply chain is

$$
\begin{aligned}
T C= & T C_{b}+T C_{v} \\
= & \frac{T}{2}\left\{h_{b} D-h_{v} D+K_{v}\left(\frac{D^{2}}{P_{v}}\left(h_{r}+h_{v}\right)+D h_{v}\right)\right\} \\
& +\frac{1}{T}\left\{S_{b}+\frac{S_{v}}{K_{v}}\right\}+T_{S} D\left(\frac{\pi}{T}-h_{b}\right) \\
& +\frac{T_{S}^{2} D}{2 T}\left(\widehat{\pi}+h_{v}\right) .
\end{aligned}
$$

This cost model can be rewritten in the following form:

$$
T C=T Y+\frac{W}{T}+A T_{S}^{2}+B T_{S}
$$

where

$$
\begin{aligned}
Y=\frac{1}{2}\left\{h_{b} D-h_{v} D\right. & \left.+K_{v}\left(\frac{D^{2}}{P_{v}}\left(h_{r}+h_{v}\right)+D h_{v}\right)\right\}, \\
W & =\left\{S_{b}+\frac{S_{v}}{K_{v}}\right\}, \\
A & =\frac{D\left(\widehat{\pi}+h_{v}\right)}{2 T}, \\
B & =D\left(\frac{\pi}{T}-h_{b}\right) .
\end{aligned}
$$

For a fixed replenishment cycle length $T,(5)$ can be optimized with respect $T_{s}$ using the concept of parabola as in [21]:

$$
T_{S}^{*}=-\frac{B}{2 A}=\frac{T h_{b}-\pi}{\hat{\pi}+h_{v}} .
$$

Substituting (7) in (5), we get

$$
T C=T Y+\frac{W}{T}-\frac{D\left(\pi-T h_{b}\right)^{2}}{2 T\left(\hat{\pi}+h_{v}\right)} .
$$

This can be further rewritten as

$$
T C=T Y+\frac{W}{T}-\frac{D \pi^{2}}{2 T\left(\hat{\pi}+h_{v}\right)}+\frac{\pi h_{b}}{\left(\hat{\pi}+h_{v}\right)}-\frac{T h_{b}^{2}}{2\left(\hat{\pi}+h_{v}\right)} .
$$

Substituting $\bar{Y}=Y-h_{b}^{2} / 2\left(\widehat{\pi}+h_{v}\right)$ and $\bar{W}=W-D \pi^{2} / 2(\widehat{\pi}+$ $h_{v}$ ) in (9), we have

$$
T C=T \bar{Y}+\frac{\bar{W}}{T}+\frac{\pi h_{b}}{\left(\hat{\pi}+h_{v}\right)} .
$$

Now, applying the algebraic procedure proposed by [16] and extended by [20], the annual total cost for the entire supply chain in (9) can be represented by factorizing the term $1 / T$, and completing the perfect square, one has

$$
T C=\frac{1}{T}\left(T^{2} \bar{Y}-2 T \sqrt{\bar{Y} \bar{W}}+\bar{W}+2 T \sqrt{\bar{Y} \bar{W}}\right)+\frac{\pi h_{b}}{\left(\widehat{\pi}+h_{v}\right)} .
$$

After further factorization, we get

$$
T C=\frac{1}{T}(T \sqrt{\bar{Y}}-\sqrt{\bar{W}})^{2}+2 T \sqrt{\bar{Y} \bar{W}}+\frac{\pi h_{b}}{\left(\hat{\pi}+h_{v}\right)} .
$$

It is worthy pointing out that (12) reaches the minimum with respect to $T$ when setting

$$
(T \sqrt{\bar{Y}}-\sqrt{\bar{W}})^{2}=0
$$


Hence, the optimal batch size $T^{*}$ is

$$
T^{*}=\sqrt{\frac{\bar{W}}{\bar{Y}}}
$$

Now, for the entire supply chain, the minimum annual total cost is given as

$$
T C=2 \sqrt{\bar{Y} \bar{W}}+\frac{\pi h_{b}}{\left(\hat{\pi}+h_{v}\right)} .
$$

The optimal batch size $T^{*}$ is a function of the integer multiplier $K_{v}$. We use the method of perfect square to drive the optimal value of this integer multiplier. Substituting for $\bar{Y}$ and $\bar{W}$ into (15), we get

$$
T C=\sqrt{2}\left\{\left(K_{v} a+b\right)\left(c+\frac{d}{K_{v}}\right)\right\}^{1 / 2}+\frac{\pi h_{b}}{\left(\hat{\pi}+h_{v}\right)},
$$

where $a=\left(\left(D^{2} / P_{v}\right)\left(h_{r}+h_{v}\right)+D h_{v}\right), b=h_{b} D-h_{v} D-h_{b}^{2} / 2(\widehat{\pi}+$ $\left.h_{v}\right), c=S_{b}-D \pi^{2} / 2\left(\widehat{\pi}+h_{v}\right)$, and $d=S_{v}$.

Rewriting (16), we get

$$
\begin{aligned}
T C= & \sqrt{2}\left\{\frac{1}{K_{v}}\left[K_{v} \sqrt{a c}-\sqrt{b d}\right]^{2}+[\sqrt{a d}+\sqrt{b c}]^{2}\right\}^{1 / 2} \\
& +\frac{\pi h_{b}}{\left(\hat{\pi}+h_{v}\right)} .
\end{aligned}
$$

From (17), setting

$$
\left[K_{v} \sqrt{a c}-\sqrt{b d}\right]^{2}=0
$$

the optimal value of the integer multiplier $K_{v}^{*}$ is derived as follows:

$$
K_{v}^{*}=\sqrt{\frac{b d}{a c}}
$$

Since the value of $K_{v}^{*}$ is a positive integer, the following condition must be satisfied:

$$
\left(K_{v}^{*}\right) \cdot\left(K_{v}^{*}-1\right) \leq\left(\frac{b d}{a c}\right) \leq\left(K_{v}^{*}\right) \cdot\left(K_{v}^{*}+1\right) .
$$

Now, we can substitute $K_{v}^{*}$ from (19) into (14) to find the optimal cycle time size $T^{*}$. This optimal value of $T^{*}$ is used to get $T_{S}^{*}$ from (7). Also, substituting $K_{v}^{*}$ from (19) into (17) derives the optimal annual total cost in the following closed form:

$$
T C^{*}=\sqrt{2}[\sqrt{a d}+\sqrt{b c}]+\frac{\pi h_{b}}{\left(\hat{\pi}+h_{v}\right)} .
$$

\section{Numerical Example}

In this section, we present a numerical example to illustrate the application of developed solution procedure. The relevant data is shown in Table 1 . In addition to this data, it is also assumed that holding cost for the raw material at the vendor is $h_{r}=0.1$.

By applying the developed hybrid geometric-algebraic method in the previous section, the results of this example are presented in Table 2.
TABLE 1: Data for the example supply chain.

\begin{tabular}{lcccc}
\hline Party & $P_{i}$ & $D$ & $h_{i}$ & $S_{i}$ \\
\hline Vendor & 1500 & 500 & 0.2 & 300 \\
Buyer & - & 500 & 1.5 & 29 \\
\hline
\end{tabular}

TABLE 2: The example solution.

\begin{tabular}{lc}
\hline Parameter & Solution \\
\hline$K_{v}$ & 3 \\
$T^{*}$ & 0.016 \\
$T_{S}^{*}$ & 0.113 \\
$T C^{*}$ & 13473.65 \\
\hline
\end{tabular}

\section{Conclusion}

In this paper, we considered a two-stage supply chain inventory model for coordinating the inventory policies between a vendor and a buyer with full information sharing and planned backorders. We used a hybrid geometric-algebraic method to drive the optimal replenishment policy and the minimum supply chain total cost in a closed form. The described model can be used by the two parties to get benefits of sharing their information and synchronizing their inventory replenishment cycle. The hybrid geometric-algebraic solution method described in this paper contributes to the trending literature that uses nontraditional derivatives based methods.

One clear limitation of the developed model is the assumption of known deterministic demand. Considering a real-world case and relaxing the restrictive model assumptions are good direction for further research. Also, the use of this hybrid geometric-algebraic method for the development of more complex generalized multistage nonserial supply chain inventory models is considered for future research.

\section{Acknowledgment}

The author would like to acknowledge the support for this research provided by the Deanship of Scientific Research: King Faisal University under Grant (14045).

\section{References}

[1] A. Banerjee, "A joint economic-lot-size model for purchaser and vendor," Decision Sciences, vol. 17, no. 3, pp. 292-311, 1986.

[2] M. Khouja, "Optimizing inventory decisions in a multi-stage multi-customer supply chain," Transportation Research E, vol. 39, no. 3, pp. 193-208, 2003.

[3] M. Ben-Daya, M. Darwish, and K. Ertogral, "The joint economic lot sizing problem: review and extensions," European Journal of Operational Research, vol. 185, no. 2, pp. 726-742, 2008.

[4] M. Khouja and S. K. Goyal, "A review of the joint replenishment problem literature: 1989-2005," European Journal of Operational Research, vol. 186, no. 1, pp. 1-16, 2008.

[5] S. K. Goyal and Y. P. Gupta, "Integrated inventory models: the buyer-vendor coordination," European Journal of Operational Research, vol. 41, no. 3, pp. 261-269, 1989. 
[6] S. K. Goyal and A. Z. Szendrovits, "A constant lot size model with equal and unequal sized batch shipments between production stages," Engineering Costs and Production Economics, vol. 10, no. 1, pp. 203-210, 1986.

[7] L. Lu, "A one-vendor multi-buyer integrated inventory model," European Journal of Operational Research, vol. 81, no. 2, pp. 312323, 1995.

[8] S. K. Goyal, "A one-vendor multi-buyer integrated inventory model: a comment," European Journal of Operational Research, vol. 82, no. 1, pp. 209-210, 1995.

[9] S. K. Goyal, "A joint economic-lot-size model for a purchaser and vendor: a comment," Decision Sciences, vol. 19, no. 1, pp. 236-241, 1988.

[10] M. A. Hoque and S. K. Goyal, "Optimal policy for a singlevendor single-buyer integrated production-inventory system with capacity constraint of the transport equipment," International Journal of Production Economics, vol. 65, no. 3, pp. 305$315,2000$.

[11] H. L. Lee, V. Padmanabhan, and S. Whang, "The bullwhip effect in supply chains," MIT Sloan Management Review, pp. 93-102, Spring 1997.

[12] J. R. Carter, B. G. Ferrin, and C. R. Carter, "The effect of lessthan-truckload rates on the purchase order lot size decision," Transportation Journal, vol. 34, no. 3, pp. 35-45, 1995.

[13] T. L. Esper and L. R. Williams, "The value of collaborative transportation management (CTM): its relationship to CPFR and information technology," Transportation Journal, vol. 42, no. 4, pp. 55-65, 2003.

[14] J.-M. Chen and T.-H. Chen, “The multi-item replenishment problem in a two-echelon supply chain: the effect of centralization versus decentralization," Computers and Operations Research, vol. 32, no. 12, pp. 3191-3207, 2005.

[15] H. M. Wee and C. J. Chung, "A note on the economic lot size of the integrated vendor-buyer inventory system derived without derivatives," European Journal of Operational Research, vol. 177, no. 2, pp. 1289-1293, 2007.

[16] L. E. Cárdenas-Barrón, "Optimizing inventory decisions in a multi-stage multi-customer supply chain: a note," Transportation Research E, vol. 43, no. 5, pp. 647-654, 2007.

[17] R. W. Grubbström, "Modelling production opportunitiesan historical overview," International Journal of Production Economics, vol. 41, no. 1-3, pp. 1-14, 1995.

[18] M. E. Seliaman, "Using complete squares method to optimize replenishment policies in a four-stage supply chain with planned backorders," Advances in Decision Sciences, vol. 2011, Article ID 745896, 9 pages, 2011.

[19] L. E. Cárdenas-Barrón, “The derivation of EOQ/EPQ inventory models with two backorders costs using analytic geometry and algebra," Applied Mathematical Modelling, vol. 35, no. 5, pp. 2394-2407, 2011.

[20] M. E. Seliaman and A. Ahmad, "A generalized algebraic model for optimizing inventory decisions in a multi-stage complex supply chain," Transportation Research E, vol. 45, no. 3, pp. 409418, 2009.

[21] J. T. Teng, L. E. Cárdenas-Barrón, and K. R. Lou, “The economic lot size of the integrated vendor-buyer inventory system derived without derivatives: a simple derivation," Applied Mathematics and Computation, vol. 217, no. 12, pp. 5972-5977, 2011.

[22] S. S. Sana, "A production-inventory model of imperfect quality products in a three-layer supply chain," Decision Support Systems, vol. 50, no. 2, pp. 539-547, 2011.
[23] K. J. Chung and L. E. Cárdenas-Barrón, “The complete solution procedure for the EOQ and EPQ inventory models with linear and fixed backorder costs," Mathematical and Computer Modelling, vol. 55, no. 11-12, pp. 2151-2156, 2012. 


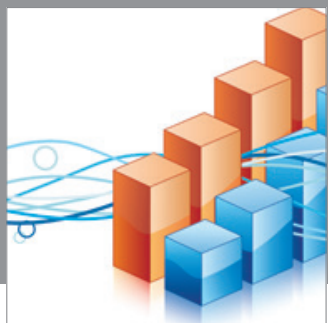

Advances in

Operations Research

mansans

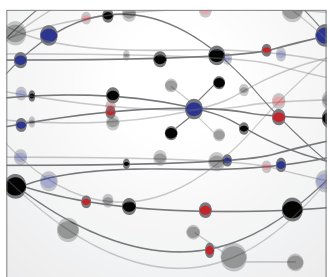

The Scientific World Journal
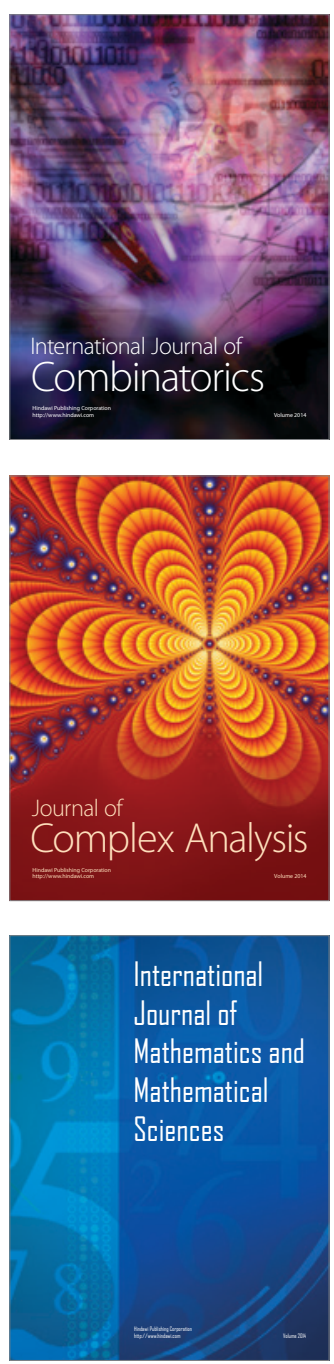
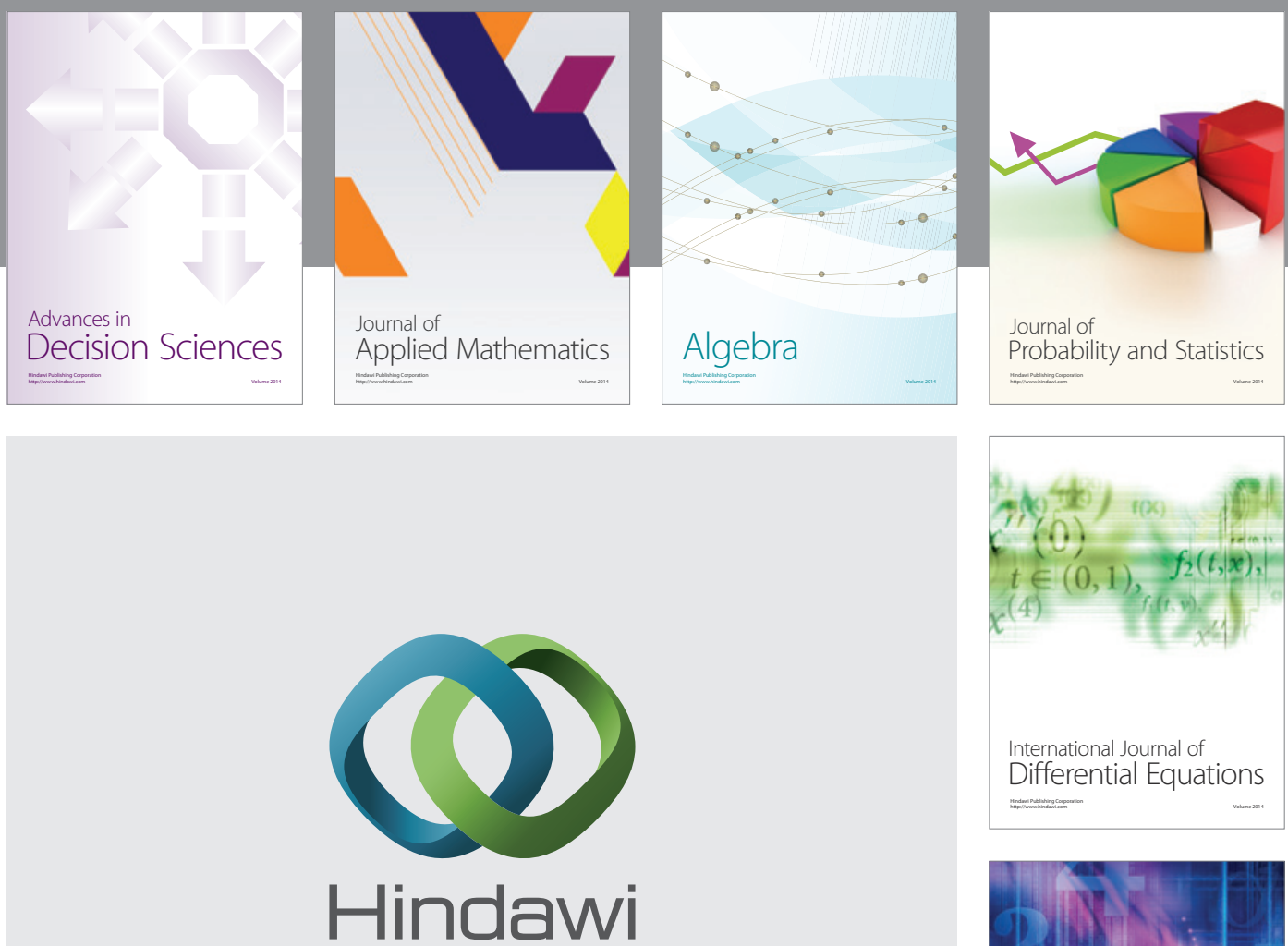

Submit your manuscripts at http://www.hindawi.com
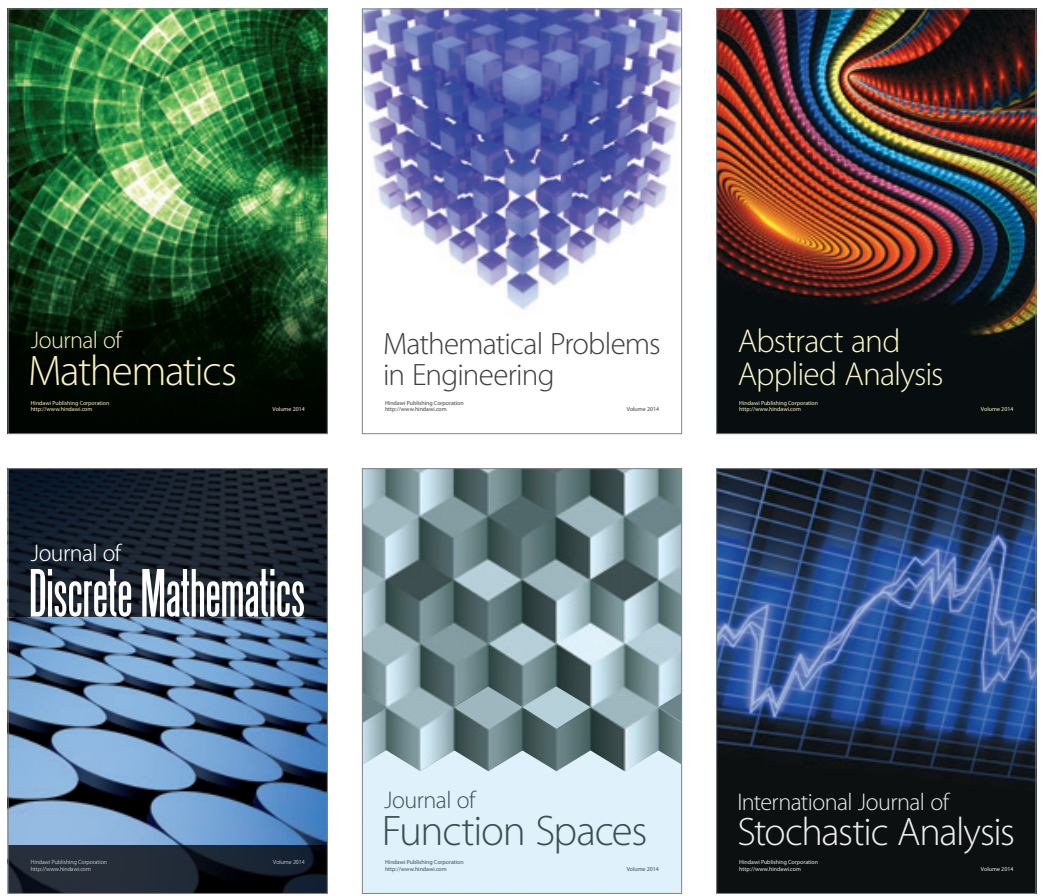

Journal of

Function Spaces

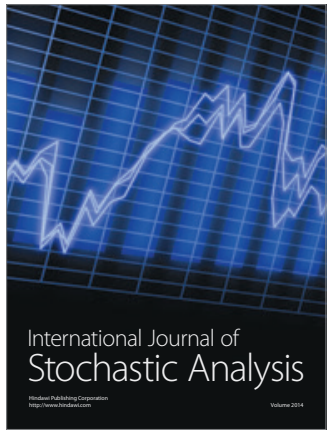

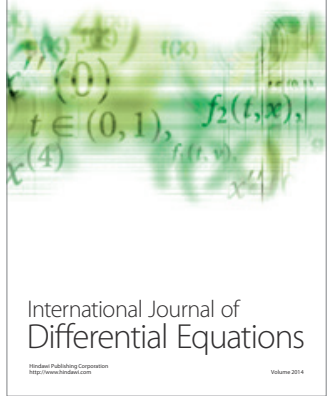
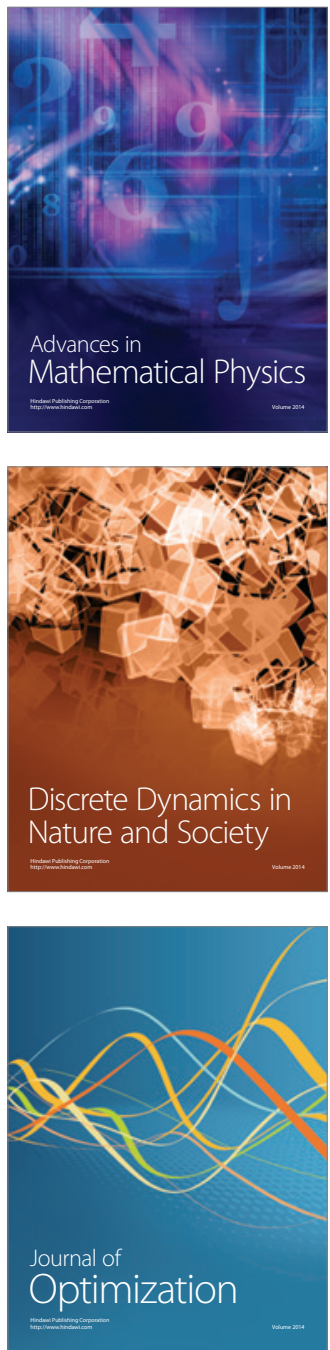